\title{
Allergy to laboratory animals in laboratory technicians and animal keepers
}

\author{
G AGRUP, ${ }^{12}$ L BELIN $^{3}$ L SJÖSTEDT, ${ }^{4}$ AND S SKERFVING ${ }^{1}$
}

From the Department of Occupational Medicine, ${ }^{1}$ University of Lund, S-221 85 Lund, Department of Occupational Dermatology, ${ }^{2}$ National Board of Occupational Safety and Health, S-171 84 Solna, Occupational Allergy Unit, ${ }^{3}$ Department of Medicine I, Sahlgren's Hospital, S-413 45 Göteborg, and Swedish Foundation for Occupational Health and Safety for State Employees, ${ }^{4}$ Statshälsan, S-221 05 Lund, Sweden

ABSTRACT The prevalence of allergy to laboratory animals (LAA) was investigated in laboratory. technicians and animal keepers. In a questionnaire 41 of 101 technicians reported symptoms pro-0 voked by work with laboratory animals. On clinical investigation 30 were found to have symptomso and signs related to contact with animals, and allergy was confirmed by radioallergosorbent tests (RAST) and skin tests in 19. All had rhinitis and 10 also had bronchial asthma. Forty seven other? technicians who had stopped working with laboratory animals showed the same relative numberș of respiratory tract symptoms and of confirmed allergy to laboratory animals as did those currently? handling animals. Seven of 23 animal keepers had work related symptoms. LAA symptoms were found in four and confirmed animal allergy in two. All four animal keepers with animal related symptoms had rhinitis, none had bronchial asthma. Positive animal RAST and skin tests were found only among people with animal related symptoms. A history of atopic disease was commoner among those with positive animal test results than among those with negative test results. Noo relation between smoking and the development of allergy to laboratory animals emerged. Simple⿻ prophylactic measures often sufficed to help technicians with animal related symptoms to remain a $\stackrel{\rho^{-}}{\Rightarrow}$ work.

In 1957 Sorrell and Gottesman described allergy to mice in a laboratory worker ${ }^{1}$ and in 1961 Rajka reported a series of 10 patients with allergy to guinea pig, rat, rabbit, and mouse. ${ }^{2}$ During the past decade allergy to laboratory animals has become a matter of increasing interest, and a clinical entity called laboratory animal allergy syndrome (LAA syndrome) has been defined. The occurrence of these allergies has been studied, and major investigations on different and often mixed occupational groups have also been performed $^{3-12}$; prevalence rates varying between $11 \%$ and $30 \%$ have been reported.

The aim of the present study was to define the prevalence of allergy to laboratory animals in two well defined occupational groups, laboratory technicians handling animals and animal keepers at the University of Lund, Sweden. The study also included technicians and animal keepers who had stopped working with animals during the past decade. These former Accepted 15 July 1985 employees were investigated to establish whether ac "healthy worker selection" existed. The clinical mani-festations (rhinitis, rhinoconjuctivitis, asthma, ando urticaria) were studied. Allergies to the following six. species were investigated; rat, mouse, rabbit, guineao pig, hamster, and cat.

The effect of the allergies on working routines ande on the ability of the sufferers to continue their work was also investigated. Work practices were studied? and hygienic improvements and prophylactic mea sures taken by the staff are reported.

The currently employed laboratory technicians in 0 whom symptoms related to laboratory animals were found were compared with the same number of tech-o nicians with no symptoms. This control group was chosen from among the currently employed tech $\frac{\text { D }}{0}$ nicians who reported no symptoms when handling animals and who had the same age and sex distribution as the LAA technicians; exposure to animals waso comparable in the two groups. 


\section{Material and methods}

All technicians working with laboratory animals and employed at the 25 research laboratories at the University of Lund and all animal keepers working at these laboratories were included. They were invited to complete a questionnaire designed to disclose symptoms related to handling animals. Information on previous and current exposure to six species (rat, mouse, guinea pig, cat, rabbit, and hamster) was sought and also details of domestic pets. Questions about rhinitis, conjunctivitis, asthma, and urticaria related to animal work, and personal or family history, or both, of atopic disease (asthma, allergic rhinitis, and atopic dermatitis) were included. Smoking habits were also noted.

Questionnaires were sent to 155 laboratory technicians, 101 currently employed and 54 who had discontinued their work in the preceding 10 years. The 54 who had stopped work had been employed at the five largest laboratories. The same questionnaire was distributed to all 24 currently employed animal keepers and to all 25 previously employed animal keepers who had stopped work during the past decade.

All those who reported animal related symptoms were invited to the department of occupational medicine, Lund, for clinical examination. All clinical examinations were performed by one of us (GA). A history with special attention to routines in animal handling was taken. The latent period (the period between starting work with animals and the first appearance of symptoms of allergy) was noted. This history was taken "blind," before the physical examination. As part of the examination alpha ${ }_{1}$ antitrypsin was measured by serum electrophoresis, and the total serum IgE was determined by paper radio immunosorbent tests (PRIST) using reagents from Pharmacia AB, Uppsala. Lung function tests were performed on a Vitalograph spirometer with recording of the forced expiratory volume in one second $\left(F E V_{1}\right)$ and the forced vital capacity (FVC). All those with pulmonary symptoms indicating bronchial obstruction or hyperreactivity were examined with a methacholine test using concentrations of $0.001,0.01$, and $0.1 \%$ of methacholine solutions and a Bernstein spirometer. A fall in the $\mathrm{FEV}_{1}$ of at least $15 \%$ after exposure to a solution of $0.1 \%$ methacholine was regarded as pathological.

Skin prick tests were performed on the volar aspect of the forearm with the following animal allergens: urine extracts from white rat and white mouse, and hair skin extracts from guinea pig, hamster, cat, and rabbit. The rat and mouse antigens are low molecular weight urinary proteins, mainly an alpha ${ }_{2}$-globulin in rat urine and a prealbumin in mouse urine. ${ }^{613}$ They were separated from tenfold concentrated urine by gel-filtration on a Sephadex G 100 column. Pooled fractions eluted as protein markers with molecular weights of ca 20000 , and concentrations of 0.5 and $1 \mathrm{mg} / \mathrm{ml}$ were used. The cat extract also contained a saliva preparation, because it has been suggested that saliva may be the best source of cat allergen. ${ }^{1415}$ The skin tests also included a standard battery of common environmental allergens-namely, four different pollen extracts (Betula pubescens, Phleum pratense, Artemisia vulgaris, and Dactylis glomerata), allergens from fish, dog, and horse, two mite species (Dermatophagoides pteronyssinus and Dermatophagoides farine), and four moulds (Alternaria iridis, Cladosporium herbarum, Penicillium notatum, and Aspergillus fumigatus). The allergens were prepared by the occupational allergy unit, Sahlgren's Hospital, Gothenburg, Pharmacia AB, Uppsala, and the Allergological Laboratory, Copenhagen.

Histamine hydrochloride, $10 \mathrm{mg} / \mathrm{ml}$, was used as a reference for prick tests, and the weal size produced was defined as +++ . Skin reactions to the allergens were compared with the histamine weal area and were classified as follows.

$$
\begin{aligned}
& 0=\text { no reaction or less then } 1 / 4 \text { of the histamine weal } \\
& \text { size, } \\
& +=1 / 4 \text { of histamine weal, } \\
& ++=1 / 2 \text { of histamine weal, } \\
& +++=\text { histamine weal, } \\
& ++++=2 \times \text { histamine weal, and } \\
& +++++=4 \times \text { histamine weal. }
\end{aligned}
$$

All plus reactions were regarded as positive.

Specific serum IgE antibodies to the laboratory animal allergens were measured with radioallergosorbent tests (RAST). Bromocyanide activated cellular discs were coupled with guinea pig, rat, and mouse allergens using standard procedures. The guinea pig extract was prepared from superficial skin scrapes, the others from urine as described above. Rabbit, cat, and hamster discs and radioactive antiIgE tracer were prepared by Pharmacia AB, Uppsala. RAST results were calculated according to the manufacturer's recommendation using a highly positive sera from a birch pollen allergen individual as an internal standard. Positive results were accordingly graded from classes 1 to 4 . In terms of radioactivity RAST class 1 corresponds to a binding to the RAST disc at about $2 \%$ of total added amount of tracer (40000 counts per $90 \mathrm{sec}$ ).

The 30 people in the control group of technicians working with laboratory animals and with no symptoms or signs associated with the animals were investigated in the same way as those with symptoms. 
Table 1 Results of RAST and skin tests to laboratory animals in 101 currently employed technicians

\begin{tabular}{llll}
\hline & No of subjects & \multicolumn{2}{l}{ Animal tests } \\
\cline { 2 - 4 } & & Positive & Negative \\
\hline Animal related symptoms & 30 & 19 & 11 \\
Other work related & 11 & 0 & 11 \\
symptoms & 30 & 0 & 30 \\
\hline Control group & &
\end{tabular}

\section{Results}

\section{CURRENTLY EMPLOYED TECHNICIANS}

All 101 technicians (4 men and 97 women, mean age 36 , range 22-58) working with laboratory animals completed the questionnaires. Forty one (two men and 39 women) reported symptoms that they related to their work and possibly to the animals. A detailed history suggested that the symptoms were related to exposure to animals in 30 people (two men and 28 women, mean age 37, range 26-58); the remaining 11 had nasal or ocular symptoms related to formaldehyde, solvents, dust, or dry air.

The symptoms varied from slight discomfort from rhinorrhoea, nasal congestion, sneezing, and conjunctival itching to severe respiratory symptoms such as cough, dyspnoea, and wheezing. The first symptoms appeared within 12 months of starting animal handling in seven people; the mean latent period was 2.3 years, range one month-seven years.

Nasal or conjunctival symptoms, or both, were the first in all those with animal related symptoms. Days or weeks after the appearance of the nasal or conjunctival symptoms many noted itching and wealing of skin at sites of animal contact. Asthma developed after several months and in two cases more than one year after the initial symptoms.

The 41 technicians with work related symptoms included 30 ( 28 women and two men) with symptoms suggestive of LAA when the clinical history was taken before the physical examination and testing. Of these, 19 (18 women and one man) showed positive RAST and skin test results to one or more laboratory animal allergens and 11 were test negative. The remaining 11

Table 2 Number of laboratory technicians exposed to the six animal species, and corresponding animal test results

\begin{tabular}{lcc}
\hline Species & No exposed & No with positive tests \\
\hline All species & 101 & 19 \\
Rat & 83 & 15 \\
Mouse & 55 & 10 \\
Rabbit & 55 & 6 \\
Guinea pig & 35 & 9 \\
Cat & 26 & 8 \\
Hamster & 1 & 9 \\
\hline
\end{tabular}

Table 3 Results of RAST and skin tests to one or more of the six species of laboratory animals in 30 laboratory technicians with respiratory symptoms. In the group with positive results one or more tests were positive

\begin{tabular}{lll}
\hline & \multicolumn{3}{l}{ Animal test results } \\
\cline { 2 - 4 } & Positive & Negative \\
\hline Rhinitis & 10 & 10 \\
Asthma and rhinitis & 9 & 1 \\
\hline
\end{tabular}

who had work related symptoms not connected with $\stackrel{\overrightarrow{.}}{-}$ animal handling showed negative animals tests. Of $\omega_{\sigma}$ the control group of 30 technicians working with ani- $\supset$ mals but with no symptoms, all showed negative $\frac{\mathbb{D}}{3}$ RAST and skin test reactions to laboratory animals $\frac{\vec{\omega}}{\omega}$ (table 1).

Table 2 shows the number of technicians working $\underset{\vec{t}}{\vec{\omega}}$ with the different animals and the number of people $N$ with positive RAST and skin tests: 15 reacted to rat 음 and 10 to mouse. Many reported that they had first $\rightarrow$ noticed sensitivity to rat and later also to mouse. Of $\overline{3}$ the 15 allergic to rats, 14 had been working with male $\frac{\infty}{3}$ animals and one worked only with mice and never $\frac{\rho}{5}$ with rats, but was strongly positive to both rat and $\vec{\varphi}$ mouse urine. Among the 10 people who reacted to $\stackrel{\infty}{\circ}$ mouse allergen, nine also reacted to rat allergen. Nine showed positive reactions to guinea pig, and all had been exposed to this animal; they were also positive to hamster allergen, although only one had been working with a hamster. Another worker had had a hamster as a domestic pet and had noticed some sensitivity before starting to work with guinea pigs. Eight were positive to cat, of whom five were working with cats. Six were positive to rabbit allergen and were

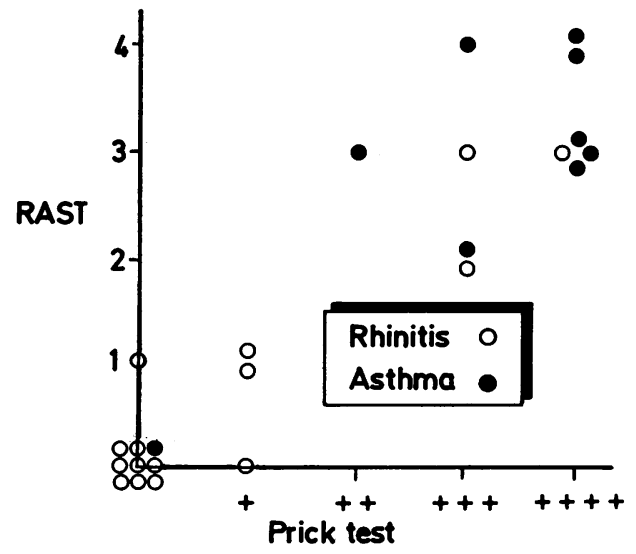

RAST and skin prick test results ( 9 negative) to rat urinary proteins in 24 laboratory technicians with respiratory symptoms caused by handling rats. Correlation coefficient $(r=0.82)$. 
Table 4 Past symptoms in 47 laboratory technicians previously working with laboratory animals

\begin{tabular}{lcl}
\hline & No of subjects & $\%$ \\
\hline Animal related symptoms & 18 & 38 \\
Stopped work owing to animal & 8 & 17 \\
related symptoms & 9 & 19 \\
Other work related symptoms & 9 & \\
\hline
\end{tabular}

working with rabbits. The highest relative frequency of allergy was to cat $(31 \%)$ and the lowest to rabbit $(11 \%)$; this difference is significant $\left(\chi^{2}=4.87, p<\right.$ $0.05)$. The relative frequencies of allergies to other animals did not differ significantly.

Table 3 presents the results of the skin tests and RAST in 20 laboratory technicians with rhinitis only and in 10 with both rhinitis and asthma. Of the 10 with asthma, nine had positive test results to the relevant animals; but only 10 of the 20 technicians with rhinitis but not asthma had positive RAST and skin tests. There was a positive correlation between the results of the skin prick tests and RAST. The people with bronchial asthma had the strongest test results. Twenty four technicians had respiratory symptoms caused by handling rats. The RAST and skin prick tests and the positive correlation between the two types of test results are illustrated in the figure. One woman with bronchial asthma, however, had negative skin and RAST tests, and was investigated for precipitating specific antibodies with negative result; she had been working exclusively with female rats.

Of the 19 people with LAA symptoms and positive animal tests, $13(68 \%)$ had a history of atopic dermatitis, rhinitis, or asthma before they started work at the laboratory or reacted to one or more allergens in the standard battery, or both. Among the 13 individuals regarded as atopic, six had a history of atopy and 12 had one or more positive skin prick tests to the standard battery, animal test excluded. Such atopic features were present in three of the 11 people with animal related symptoms but with negative animal RAST and skin tests $(27 \%)$. Of the 30 with no animal related symptoms, six $(20 \%)$ had a history of atopic disease or a positive reaction to a standard test, or both. Thus atopy was commoner among those with positive tests to laboratory animal allergens $\left(\chi^{2}=\right.$

\section{$12.07, \mathrm{p}<0.001)$.}

Smoking habits did not differ significantly between those with and those without sensitivity to laboratory animals. The proportion of smokers was roughly the same in both groups ( $47 \%$ and $60 \%$ respectively), the average duration of history of smoking was similar (15 and 16 years), and almost the same number had given up smoking in each group.

Alpha $_{1}$-antitrypsin was normal in every person investigated. The total serum IgE (PRIST) was raised in one of the 20 people with rhinitis, and in four of the 10 with asthma. All showing negative animal tests had normal total serum IgE values.

FEV $_{1}$ and FVC were normal in all those with rhinitis only and in nine of the 10 people with bronchial asthma. All those with symptoms and signs of bronchial asthma had positive methacholine test results, however.

All 30 currently employed technicians with LAA symptoms had modified their working conditions in order to carry on with their work. Many alleviated their discomfort by using masks, gloves, and long sleeves, avoided fetching the animals, and did not shave them. Fume cupboards were often used. Four confined themselves to surgical work only and used gloves and mask.

Seventeen technicians had sought medical advice because of their symptoms. Only one had been investigated for allergy, and none had claimed workers' compensation. Six had had sick leave owing to their allergy, but never for longer than two months. Most had received informal medical advice from their medical collaborators, and many took an antihistamine before handling animals.

\section{PREVIOUSLY EMPLOYED TECHNICIANS}

At five laboratories 54 technicians, all women, had discontinued working with animals during the preceding 10 years; 47 of them $(87 \%)$ completed the questionnaire and 28 of these reported symptoms related to their former work. Eight had given up their jobs because of symptoms related to animal handling (table 4).

All those who reported work related symptoms were interviewed by telephone, and $\mathbf{1 8}$ gave a history highly suggestive of allergy to laboratory animals.

Table 5 Comparison of the occurrence of work related symptom, animal related symptoms, and test confirmed allergies to laboratory animals in technicians currently working with animals and in those who had discontinued animal handling

\begin{tabular}{lclcr}
\hline & No exposed & $\begin{array}{l}\text { No with work related } \\
\text { symptoms }\end{array}$ & $\begin{array}{l}\text { No with animal related } \\
\text { symptoms }\end{array}$ & $\begin{array}{l}\text { No with positive animal } \\
\text { tests }\end{array}$ \\
\hline $\begin{array}{l}\text { Currently employed } \\
\text { Previously employed }\end{array}$ & 101 & 41 & 30 & 19 \\
Total & 47 & 28 & 6 & 48 \\
\hline
\end{tabular}


Fifteen were examined clinically; five had symptoms and signs of bronchial asthma and 10 of rhinitis only; six showed positive RAST and skin test reactions to laboratory animals, four of the five with bronchial asthma and two who had had only nasal symptoms. In all four with bronchial asthma caused by allergy to laboratory animals the asthma persisted after stopping work, and another with negative test results who had reported asthmatic symptoms when handling the animals also had persistent asthma. Methacholine tests were positive in all those with asthma.

Table 5 shows the symptoms of asthma and rhinitis and the results of animal skin and RAST tests in technicians with current symptoms resulting from handling animals and in technicians in whom previous work with animals produced symptoms. Symptoms were equally common in the two groups, and there is no significant difference in the number of proved allergies.

\section{ANIMAL KEEPERS}

Twenty three (14 men and 9 women, mean age 36, range 20-65) of the 24 currently employed animal keepers responded to the questionnaire. Seven (four men and three women) reported symptoms that they suspected to be caused by allergy to laboratory animals. Detailed histories showed that four (one man and three women) of the seven suffered from sneezing, rhinorrhoea, and nasal congestion or conjunctival itching or both, when handling animals. None had symptoms of bronchial asthma. Two women had contact urticaria caused by rats. The animal species reported to produce symptoms were in all four cases rat, in two cases rat and mouse, and in one case rat and guinea pig.

Positive RAST and skin test reactions occurred in two women, in one to rat only and in the other to all six species. Skin tests and RAST tests parallelled each other. The first symptoms appeared within two years of starting animal handling $(1.5$ and 2 years respectively). The two women with positive tests were those with a history of contact urticaria.

The remaining three people had symptoms not related to animal handling, and gave a history of nasal or conjunctival symptoms, or both, caused by woodshavings, dust, detergents, and organic solvents.

Thus seven of the 23 currently employed animal $\stackrel{\otimes}{\circ}$ keepers had work related symptoms. Four had symptoms caused by handling animals, two with positive $\stackrel{\vec{S}}{\vec{S}}$ and two with negative animal test reactions. All four $\overrightarrow{0}$ had rhinitis or rhinoconjunctivitis but none had bron- $\overline{0}$ chial asthma. Of the 101 laboratory technicians, $10 \frac{\mathrm{F}}{\mathrm{s}}$

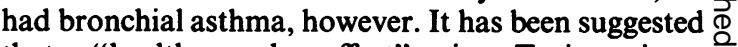
that a "healthy worker effect" exists. To investigate whether such an effect could be more pronounced in animal keepers than in laboratory technicians we sent $\vec{\circ}$ the same questionnaire to all 25 previously employed $\overrightarrow{\vec{\omega}}$ animal keepers who had stopped working with ani- $\omega$ mals during the preceding 10 years. Answers were $\stackrel{\circ}{\circ}$ returned by 18 ( 13 women and 5 men). Eight with 3 suspect histories were interviewed, investigated, and $\vec{\omega}$ tested. Five (four women and one man) had animal $\dot{\omega}$ related symptoms, and two women had positive test $\vec{\theta}$ reactions (table 6). One man with a characteristic his- $N$ tory of rhinitis while working with animals had 9 retired at 65 and later developed bronchial asthma; on investigation he had a negative response to animal $\vec{z}$ allergens.

The four animal keepers (two currently and two previously employed) with positive tests to laboratory $\overrightarrow{0}$ animals were all young women, mean age 29 . The sex difference is not statistically significant, however $\left(\chi^{2}\right.$. $=3.83, \mathrm{p}>0.05$ ).

Atopy was commoner among animal keepers with positive animal tests ( $50 \%$, two of four) than among those with negative tests $(17 \%$, five of 30$)$. The difference is not significant, possibly owing to the small numbers.

\section{Discussion}

In the questionnaires $41 \%$ of the 101 currently $\frac{\mathbb{D}}{3}$ employed laboratory technicians reported symptoms related to work with animals. This figure, however, was reduced to $30 \%$ when the symptoms were evaluated at clinical examination. The difference is explained mainly by the fact that the clinical history at 0 the time of examination was able more critically to $\rightarrow$ define the time relation between working with animals and the appearance of symptoms. Among the 30 con-

Table 6 Comparison of the occurrence of work related symptoms, animal related symptoms, and test confirmed allergies in animal keepers currently working with animals and in people who had stopped handling animals

\begin{tabular}{|c|c|c|c|c|}
\hline & No exposed & $\begin{array}{l}\text { No with work related } \\
\text { symptoms }\end{array}$ & $\begin{array}{l}\text { No with animal related } \\
\text { symptoms }\end{array}$ & $\begin{array}{l}\text { No with positive animal } \\
\text { tests }\end{array}$ \\
\hline $\begin{array}{l}\text { Currently employed } \\
\text { Previously employed }\end{array}$ & $\begin{array}{l}23 \\
18\end{array}$ & $\begin{array}{l}7 \\
8\end{array}$ & $\begin{array}{l}4 \\
5\end{array}$ & 2 \\
\hline Total & 41 & 15 & 9 & 4 \\
\hline
\end{tabular}


sidered to have symptoms from the respiratory tract definitely related to handling animals 19 showed positive RAST and skin test reactions to one or more laboratory animals and nine had bronchial asthma. Only one with bronchial asthma showed negative test reactions. All the others with negative test reactions had rhinitis or rhinoconjunctivitis only. There was a definite tendency to bronchial symptoms among people with strongly positive test results.

Among the 23 animal keepers $30 \%$ reported symptoms related to animal keeping, but this figure was reduced to $17 \%$ at clinical examination; $9 \%$ of the animal keepers showed positive animal RAST and skin tests. All four with symptoms of LAA had rhinitis only and none of the currently employed animal keepers had bronchial asthma.

The prevalence of confirmed animal allergy in animal keepers $(2 / 23)$ was similar to that encountered in the laboratory technicians (19/101). This was surprising since the animal keepers probably have a greater exposure to allergens than the technicians. Primary selection could occur, because people with a history of allergic symptoms may be less eager to take suich employment. In fact none of the currently employed animal keepers had had asthma in childhood, whereas among the technicians studied three had had asthma in childhood and two later developed bronchial asthma on handling laboratory animals.

The nasal and conjunctival symptoms among those showing negative animal RAST and skin test reactions and the bronchial asthma in the woman showing negative animal tests could have been nonallergic. The history of acquired reactivity to laboratory animals similar to that reported among the test positive subjects, however, strongly suggests that the symptoms were of allergic nature. Quite possibly, the allergen preparations used in the skin testing and RAST may have been inadequate for demonstratìng certain allergies.

Figures for the prevalence of allergy to laboratory animals have been reported in other investigations. Cockcroft et al, in a study on 179 workers at three medical research establishments, found a prevalence of $27 \%$ among people working with laboratory animals and who had symptoms related to this work. ${ }^{9}$ The group also included some who had previously worked with laboratory animals but were not currently exposed: $16 \%$ showed positive test reactions to one or more of five different species of laboratory animals. Slovak and Hill reported that $30 \%$ of 146 men and women in different work categories exposed to laboratory animals in a pharmaceutical company had symptoms related to this work. ${ }^{10}$ Only $46 \%$ of those with symptoms showed positive skin reactions to allergens from the relevant species.
The present investigation reports prevalence figures in two well defined occupational groups, and our figures are similar to those in the two earlier studies. We looked for healthy worker effect but found that the proportions of allergic symptoms and positive tests in the group currently working with animals were the same as in those who had abandoned animal handling.

All those who were allergic to rat allergens had been working with mature male animals, which produce the most potent allergen. ${ }^{613}$ Some technicians with mouse allergy had not been working with this species but with rats, indicating some cross sensitisation between rat and mouse urine. ${ }^{61113} \mathrm{~A}$ cross sensitivity also seems to exist between guinea pig and hamster, because all nine people allergic to guinea pig also reacted to hamster, although only one had had occupational contact with hamster and only one had a hamster as a domestic pet. The number of positive tests to rabbit and cat might suggest that cat was the more allergenic of the two. Four technicians, however, had had a cat as a domestic pet but nobody had owned a rabbit. The higher figure for cat hypersensitivity was therefore probably related to closer contact, which is more usual with this species.

The average latent period before appearance of the symptoms and signs was about two years and, as in other studies on laboratory animal allergy, nasal symptoms consistently appeared before bronchial asthma. 67911

The effect of smoking may be disregarded because smoking habits were roughly the same in people with and without sensitivity to laboratory animals.

Atopy (a history of atopic disease or positive test reactions, or both, to allergens in the standard battery) was significantly commoner in technicians with positive RAST and skin test reactions to the animal allergens.

Detailed interviews and inspection of many laboratories resulted in simple prophylactic measures that helped many technicians to keep on working with animals, but comprehensive changes in working conditions were sometimes necessary. Among those who had given up animal handling most could make use of their training in other laboratory fields.

From the interviews with the currently and previously employed animal keepers with allergies to laboratory animals we gained the impression that animal keepers have more difficulties than technicians in managing and modifying their occupational situation in order to prevent symptoms. The two previously employed animal keepers with positive animal test results had left their employment because of their animal induced symptoms.

The advisability of animal handling by allergic peo- 
ple may be questioned, however, because continued contact with animals may raise the level of sensitivity; slight symptoms to animal allergy could contribute a warning for the risk of developing bronchial symptoms.

This study was supported by a grant from the Walter, Ellen, and Lennart Hesselman Foundation for Scientific Research.

Requests for reprints to: Gun Agrup, MD, Department of Occupational Medicine, University of Lund, S-221 85 Lund, Sweden.

\section{References}

${ }^{1}$ Sorrell AH, Gottesman J. Mouse allergy. Case report. Ann Allergy 1957;15:662-3.

${ }^{2}$ Rajka G. Ten cases of occupational hypersensitivity to laboratory animals. Acta Allergol 1961;16:168-76.

${ }^{3}$ Lincoln TA, Bolton NE, Garrett AS Jr. Occupational allergy to animal dander and sera. $J$ Occup Med 1974;16:465-9.

${ }^{4}$ Lutsky II, Neuman I. Laboratory animal dander allergy: I. An occupational disease. Ann Allergy 1975;35:201-5.

${ }^{5}$ Taylor G, Davies GE, Altounyan REC, et al. Allergic reactions to laboratory animals. Nature 1976;260:280.

${ }^{6}$ Newman Taylor A, Longbottom JL, Pepys J. Respiratory allergy to urine proteins of rats and mice. Lancet 1977;ii:847-9.

${ }^{7}$ Gross NJ. Allergy to laboratory animals: epidemiologic, clinical, and physiologic aspects, and a trial of croinolyn in its management. J Allergy Clin Immunol 1980;66:158-65.

${ }^{8}$ Davies GE, McArdle LA. Allergy to laboratory animals: a survey by questionnaire. Int Arch Allergy Appl Immunol 1981;64:302-7.

${ }^{9}$ Cockcroft A, McCarthy P, Edwards J, Andersson N. Allergy in laboratory animal workers. Lancet 1981;i:827-30.

${ }^{10}$ Slovak AJM, Hill RN. Laboratory animal allergy: a clinical survey of an exposed population. Br J Ind Med 1981;38:38-41.

11 Davies GE, Thompson AV, Niewola Z, et al. Allergy to laboratory animals: a retrospective and a prospective study. $\mathrm{Br} J$ Ind $\mathrm{Med}$ 1983;40:442-9.

${ }^{12}$ Lutsky II, Kalbfleisch JH, Fink JN. Occupational allergy to laboratory animals: employer practices. J Occup Med 1983;25:372-6.

${ }^{13}$ Longbottom JL. Purification and characterization of allergens from the urines of mice and rats. In: Oehling A, Mathov E, Glazer I, eds. Advances in allergology and immunology. New York: Pergamon Press, 1980:483-90.

${ }^{14}$ Viander M, Valovirta E, Vanto T, Koivikko A. Cross-reactivity of cat and dog allergen extracts. RAST inhibition studies with special reference to the allergenic activity in saliva and urine. Int Arch Allergy Appl Immun 1983;71:252-60.

${ }^{15}$ Didierlaurent A, Foglietti MJ, Guerin B, Hewitt BE, Percheron F. Comparative study on cat allergens from fur and saliva. Int Arch Allergy Appl Immun 1984;73:27-31.

\section{Vancouver style}

All manuscripts submitted to the $\mathrm{Br} J$ Ind $\mathrm{Med}$ should conform to the uniform requirements for manuscripts submitted to biomedical journals (known as the Vancouver style).

The $\mathrm{Br} J$ Ind Med, together with many other international biomedical journals, has agreed to accept articles prepared in accordance with the Vancouver style. The style (described in full in $\mathrm{Br}$ Med J, 24 February 1979, p 532) is intended to standardise requirements for authors.

References should be numbered consecutively in the order in which they are first mentioned in the text by Arabic numerals above the line on each occasion the reference is cited (Manson' confirmed other reports ${ }^{2-5} \ldots$..). In future references to papers submitted to the $\mathrm{Br} J$ Ind Med should include: the names of all authors if there are six or less or, if there are more, the first three followed by et al; the title of journal articles or book chapters; the titles of journals abbreviated according to the style of Index Medicus; and the first and final page numbers of the article or chapter.

Examples of common forms of references are:

' International Steering Committee of Medical Editors. Uniform requirements for manuscripts submitted to biomedical journals. Br Med J 1979; 1:532-5.

2 Soter NA, Wasserman SI, Austen KF. Cold urticaria: release into the circulation of histamine and eosinophil chemotactic factor of anaphylaxis during cold challenge. $N$ Engl $J$ Med 1976; 294:687-90.

3 Weinstein L, Swartz MN. Pathogenic properties of invading micro-organisms. In: Sodeman WA Jr, Sodeman WA, eds. Pathologic physiology: mechanisms of disease. Philadelphia: W B Saunders, 1974:457-72. 